\title{
Heritability of Productivity Elements of Chickpeas and its Importance for Practical Breeding
}

\section{Svetlana Kuzmina, Nina Kazydub, and Vladimir Panchenko}

Omsk SAU, ul. Institutskaya ploshchad, 1, Omsk, Russia

ORCID:

Svetlana Kuzmina: http://orcid.org/0000-0002-2256-0434

\section{Abstract}

This study examined the genetics of the variability in quantitative traits and showed the possibility of selecting hybrids with a new, more favorable combination of traits, which is of practical interest for breeding. The main goal of our research was to determine the coefficients of heritability by the mass of seeds and the number of beans per plant in hybrid combinations of chickpeas, which allowed establishing the potential of parental varieties in the transfer of valuable genes responsible for plant productivity to

Corresponding Author: Svetlana Kuzmina sp.kuzmina@omgau.org

Published: 5 April 2021

Publishing services provided by Knowledge E

(c) Svetlana Kuzmina et al. This article is distributed under the terms of the Creative Commons Attribution License, which permits unrestricted use and redistribution provided that the original author and source are credited.

Selection and Peer-review under the responsibility of the DonAgro Conference Committee. offspring and expanding the spectrum of plant genetic diversity. The experiments were conducted in the fields of the educational and experimental farm of the Omsk State Agrarian University in the southern forest-steppe of the Omsk region in 2016-2018. The research included 6 chickpea samples with a complex of valuable traits from the Federal Research Center of the All-Russian Institute of Plant Genetic Resources named after N.I. Vavilov (VIR, St. Petersburg) and 8 hybrid combinations obtained on their basis. It was found that the mass of seeds per plant was characterized by low heritability $(\mathrm{H} 2=22.8 \%)$ and the number of beans per plant was high $(\mathrm{H} 2=54.0 \%)$. The variability of the mass of seeds per plant was largely paratypical and was influenced by environmental conditions; the variability in the number of beans per plant was due to genetic factors and indicated a high genetic diversity in the studied splitting chickpea populations. Selection based on the number of beans per plant was highly effective even in early generations of the hybrids. Selection by the mass of seeds from the plant was ineffective; it should be carried out in later hybrid generations under favorable growing conditions. The selection of valuable genotypes was most successful in hybrid chickpea populations by seed weight per plant: C-35 x ILC-2394, C-80 x ILC-2394, C-27 x ILC-2394, and by the number of beans per plant: C-27 x ILC-2394, C-27 x ILC-2402

Keywords: chickpeas, heritability, selection, genetics, productivity

\section{Introduction}

The interest of agricultural enterprises and peasant farms in chickpeas in the West G OPEN ACCESS 
and cold resistance, adaptability for harvesting, high nutritional value and multiple uses for food purposes [1-3]. However, the zoned varieties of chickpea under the conditions of the Omsk region do not meet the requirements of modern agriculture in terms of ripening and productivity $[4,5]$. A collection of chickpea samples from different ecological and climatic zones can be the starting material for creating new varieties $[6,7]$.

In solving the problem of accelerating the creation of new varieties of this crop for the West Siberian region [8-10]. It is of great importance to use genetic and statistical methods of assessment, in particular, to determine the heritability of valuable traits in order to obtain practical recommendations for the selection of unique genotypes in splitting hybrid populations [11-13].

The phenotypic manifestation of selectively valuable traits in chickpea is formed as a result of the interaction of the genotype and environmental conditions [14-16]. Heritability characterizes the genetic condition of a trait. To select genotypes with the desired traits, it is necessary to focus on traits with high heritability [17-19]. The higher the heritability coefficient, the wider the genetic diversity, the greater the proportion of phenotypic diversity due to genotypic variability. The lower the heritability coefficient, the more significant is the influence of environmental conditions (modification variability) for the formation of the trait, and the genetic diversity is not great [20-22]. At high values of the coefficient of heritability, mass selection will be effective, and individual selection at its low values.

The main goal of our research was to determine the coefficients of heritability by the mass of seeds and the number of beans per plant in hybrid populations of chickpea, which makes it possible to establish the potential of parental forms in the transfer of valuable genes responsible for plant productivity, offspring and expansion of the spectrum of plant genetic diversity.

\section{Methods and Equipment}

The experimental part of the work was carried out in the educational and experimental farm of the Omsk State Agrarian University together with the Center for Collective Use "Selection and seed production of field crops" in the southern forest-steppe of the Omsk region (2016-2018). The object of research was the collection samples obtained from the Federal Research Center of the All-Russian Institute of Plant Genetic Resources named after N.I. Vavilov (VIR, St. Petersburg) with a complex of valuable features: ILC-2394 
(Turkey), ILC-2402 (Bulgaria), C-27 (Uzbekistan), C-35 (Krasnodar), C-82 (Uzbekistan), C80 (Azerbaijan) and 8 hybrid populations of the second generation obtained with their participation. Sowing was carried out in the 2 nd decade of May at a depth of $5 \mathrm{~cm}$. The repetition was four-fold. The number of seeds in each repetition in parental forms was 20 pcs., in F2 that was 60 pcs. Plant nutrition area was $10 \times 60 \mathrm{~cm} 2$. The counts and observations were carried out in accordance with the "Methodological instructions for the study of the collection of grain legumes" (1975). Statistical processing was carried out according to the methodology described in the manual by B.A. Dospekhov. The heritability coefficients in a broad sense were determined by the formula of [23].

\section{Results}

The weather conditions during the years of the experiments were different: in 2016 and 2018 it was slightly arid (GTC = 1.01 and 1.1, respectively), in 2017 it was arid (GTC 0.72).

Of great importance in the selection of chickpeas for yield is the mass of seeds and the number of beans per plant. During our research, the weight of seeds per plant in chickpea varied from 4.6 to $26.3 \mathrm{~g}$ and varied significantly depending on the weather conditions.

The most favorable conditions for the growth and development of chickpea plants were the conditions of 2016. The aridity of the second half of the growing season contributed to a more friendly and faster maturation of plants and high productivity. The weight of seeds per plant of hybrids varied from 17.1 to $26.3 \mathrm{~g}$ and averaged $22.4 \mathrm{~g}$, in maternal forms it varied from 12.2 to $20.1 \mathrm{~g}$ (average $15.8 \mathrm{~g}$ ), in testers it ranged from 21.7 to $28.6 \mathrm{~g}$ (the average weight was $25.2 \mathrm{~g}$ ) (Table 1). There were significant differences both between parental forms and between hybrids. Plants from hybrid combinations had the maximum seed productivity: C-35 x ILC-2394 (26.3 g), C-25 x ILC-2402 (25.8 g), C-27 x ILC-2394 (25.2 g).

Year 2017 was characterized by excessive soil and air moisture in July and September, which negatively affected the formation of crop yields. The mass of seeds per plant decreased by $16.0 \mathrm{~g}$ and averaged $6.4 \mathrm{~g}(5.2-7.8 \mathrm{~g})$, in maternal forms it decreased by $8.5 \mathrm{~g}$ ( $7.3 \mathrm{~g}$ on average), in testers it reduced by $17 \mathrm{~g}$ ( $8.1 \mathrm{~g}$ on average). The largest mass of seeds per plant was in hybrid combinations: C-80 x ILC-2394 (7.8 g), C-35 x ILC-2402 (7.1 g).

The conditions in 2018 turned out to be extremely unfavorable for chickpea plants. For instance, torrential rains against the background of low air temperatures in late July-August led to prolonged flowering, damage to plants by fusarium and a significant 
decrease in productivity and its elements. Compared to the most favorable 2016, the productivity of hybrid plants decreased by $17.2 \mathrm{~g}$ and averaged $5.2 \mathrm{~g}$, in maternal forms it decreased by $9.9 \mathrm{~g}$ ( $5.9 \mathrm{~g}$ on average), in testers it reduced by $17.7 \mathrm{~g}$ ( $7.4 \mathrm{~g}$ on average). The most productive under stress conditions were the hybrid combinations C-27 x ILC-2402 (5.8 g), C-35 x ILC-2394 (5.7 g).

The coefficient of heritability, the mass of seeds per plant in different hybrid populations of chickpea over the years of testing varied from 14.6 to $31.6 \%$ and on average had a low value $(\mathrm{H} 2=22.8 \%)$. The low heritability of seed productivity in chickpea is probably due to a significant proportion of paratypical variability of the trait. Only $22.8 \%$ of the variability of the trait under study is due to genetic factors and mainly depends on environmental conditions. The low heritability ratio may also indicate a reduced genetic diversity in the studied chickpea populations. Thus, selection on this basis will be ineffective. In order to exclude the loss of valuable forms of highly productive plants, it is advisable to carry out individual selection in later hybrid generations.

TABLE 1: Seed weight per plant in hybrid combinations of chickpea, $\mathrm{g}$

\begin{tabular}{|c|c|c|c|c|}
\hline $\begin{array}{l}\text { Sample, hybrid } \\
\text { combination }\end{array}$ & 2016 & 2017 & 2018 & Mean \\
\hline \multicolumn{5}{|c|}{ Parent forms } \\
\hline $\mathrm{C}-27$ & 18.2 & 8.8 & 6.9 & 11.3 \\
\hline C-35 & 20.1 & 6.3 & 5.4 & 10.6 \\
\hline C-82 & 12.2 & 8.6 & 6.2 & 9.0 \\
\hline C-80 & 12.8 & 5.6 & 5.1 & 7.8 \\
\hline ILC-2394 & 21.7 & 7.4 & 5.6 & 11.6 \\
\hline ILC-2402 & 28.6 & 8.8 & 9.2 & 15.5 \\
\hline $\operatorname{Lim} \min \div \max$ & $12.2-28.6$ & $5.6-8.8$ & $5.1-9.2$ & 7.8-15.5 \\
\hline Mean & 18.9 & 7.6 & 6.4 & 10.9 \\
\hline $\mathrm{LSD}_{05}$ & 2.84 & 1.14 & 0.96 & 1.64 \\
\hline \multicolumn{5}{|c|}{ Hybrid combinations $F_{2}$} \\
\hline C-27 x ILC-2394 & 25.2 & 6.4 & 5.2 & 12.3 \\
\hline C-27 x ILC-2402 & 22.6 & 6.4 & 5.8 & 11.6 \\
\hline C-35 x ILC-2394 & 26.3 & 5.7 & 5.7 & 12.6 \\
\hline C-35 x ILC-2402 & 25.8 & 7.1 & 5.1 & 12.7 \\
\hline C-82 x ILC-2394 & 17.1 & 5.2 & 4.6 & 9.0 \\
\hline C-82 x ILC-2402 & 24.2 & 6.5 & 4.5 & 11.7 \\
\hline C-80 x ILC-2394 & 18.6 & 7.8 & 5.1 & 10.5 \\
\hline C-80 x ILC-2402 & 19.2 & 6.3 & 5.4 & 10.3 \\
\hline Lim $\min \div \max$ & $17.1-26.3$ & $5.2-7.8$ & $4.5-5.8$ & $9.0-12.7$ \\
\hline Mean & 22.4 & 6.4 & 5.2 & 11.3 \\
\hline $\mathrm{LSD}_{05}$ & 3.36 & 0.96 & 0.78 & 1.70 \\
\hline
\end{tabular}


TABLE 2: Heritability of seed mass per chickpea plant, \%

Hybrid
combination
C-27 x ILC-2394
C-27 x ILC-2402
C-35 x ILC-2394
C-35 x ILC-2402
C-82 x ILC-2394
C-82 x ILC-2402
C-80 x ILC-2394
C-80 x ILC-2402
Lim min $\div$ max
Mean

\begin{tabular}{|c|}
\hline 2016 \\
\hline 31.6 \\
\hline 24.1 \\
\hline 31.5 \\
\hline 26.5 \\
\hline 25.2 \\
\hline 29.7 \\
\hline 27.0 \\
\hline 23.2 \\
\hline $23.2-31.6$ \\
\hline 27.3 \\
\hline
\end{tabular}

\begin{tabular}{|c|}
\hline 2017 \\
\hline 19.8 \\
\hline 18.2 \\
\hline 20.8 \\
\hline 23.5 \\
\hline 16.3 \\
\hline 18.7 \\
\hline 30.0 \\
\hline 21.9 \\
\hline $16.3-30$ \\
\hline 21.1 \\
\hline
\end{tabular}

\begin{tabular}{|c|}
\hline 2018 \\
\hline 20.8 \\
\hline 18.0 \\
\hline 25.9 \\
\hline 17.5 \\
\hline 19.5 \\
\hline 14.6 \\
\hline 23.8 \\
\hline 18.9 \\
\hline $14.6-25.9$ \\
\hline 19.9 \\
\hline
\end{tabular}

\begin{tabular}{|c|}
\hline Mean \\
\hline 24.0 \\
\hline 20.1 \\
\hline 26.1 \\
\hline 22.5 \\
\hline 20.3 \\
\hline 21.0 \\
\hline 26.9 \\
\hline 21.3 \\
\hline $20.1-26.9$ \\
\hline 22.8 \\
\hline
\end{tabular}

It should be noted that the value of the heritability coefficient in different years was influenced by the conditions of plant growth. Thus, under more favorable conditions, heritability increased due to an increase in genetic diversity in the splitting hybrid populations of chickpea; therefore, phenotypic variability was largely due to the genotype. For instance, in favorable conditions of 2016 , the heritability coefficient averaged $27.3 \%$, and in extreme conditions for chickpea in 2018, it decreased to 19.9\%. Selection on this basis is recommended to be carried out in more favorable growing conditions for the culture.

The level of phenotypic manifestation of the number of beans per plant also depended on hydrothermal conditions. The studied indicator during the research in different hybrid combinations varied from 22.4 to 102.2 pcs. (58.7 pcs. on average).

In 2016, the number of beans per plant in hybrids varied from 72 to 102.2. (an average of 91.9 pcs.), in maternal forms it ranged from 48.6 to 87.2 pcs. (62.8 pieces on average), in testers it varied from 93.3 to 105.7 pieces. (99.5 pcs. on average) (Table 3). Maternal forms and hybrids significantly differed among themselves in the number of beans. The maximum number of beans was in hybrid populations with the participation of the tester C-35 x ILC-2394 (102 pcs.) and C-27 x ILC-2394 (98 pcs.).

In 2017, the number of beans in chickpea hybrids decreased by 39.1 pieces. and amounted to an average of 52.8 pcs. (from 46.6 to 68.2 pcs.), in maternal forms decreased by 3.8 pcs. ( 59.8 pcs. on average), for testers it reduced by 59.2 pcs. (40.3 pcs. on average). The largest number of beans per plant was observed in hybrid combinations: C-80 x ILC-2394 (68.2 pcs.) and C-27 x ILC-2394 (57.1 pcs.).

In 2018, compared with the most favorable 2016, the number of beans in chickpea hybrids decreased by 60.6 pcs. and amounted to an average of 31.3 pcs (from 22.4 to 
TABLE 3: Number of beans per plant in hybrid combinations of chickpeas, pcs.

\begin{tabular}{|c|c|c|c|c|}
\hline $\begin{array}{l}\text { Sample, hybrid } \\
\text { combination }\end{array}$ & 2016 & 2017 & 2018 & Mean \\
\hline \multicolumn{5}{|c|}{ Parent forms } \\
\hline$C-27$ & 54.2 & 48.6 & 26.8 & 43.2 \\
\hline C-35 & 87.2 & 60.1 & 24.3 & 57.2 \\
\hline C-82 & 48.6 & 55.9 & 36.2 & 46.9 \\
\hline C-80 & 61.1 & 71.0 & 29.2 & 53.7 \\
\hline ILC-2394 & 105.7 & 48.3 & 36.1 & 63.3 \\
\hline ILC-2402 & 93.3 & 32.3 & 28.0 & 51.1 \\
\hline Lim $\min \div \max$ & $48.6-105.7$ & $32.3-71.0$ & $24.3-36.2$ & $43.2-63.3$ \\
\hline Mean & 75.0 & 52.6 & 30.1 & 52.6 \\
\hline $\mathrm{LSD}_{05}$ & 11.3 & 7.9 & 4.5 & 7.8 \\
\hline \multicolumn{5}{|c|}{ Hybrid combinations $F_{2}$} \\
\hline C-27 x ILC-2394 & 98 & 57.1 & 38.3 & 64.5 \\
\hline C-27 x ILC-2402 & 96 & 48.6 & 28.8 & 57.8 \\
\hline C-35 x ILC-2394 & 102.2 & 51.2 & 38.6 & 63.9 \\
\hline C-35 x ILC-2402 & 94 & 54.1 & 22.4 & 56.8 \\
\hline C-82 x ILC-2394 & 88 & 49.6 & 32.4 & 56.7 \\
\hline C-82 x ILC-2402 & 72 & 47.1 & 28.2 & 49.1 \\
\hline C-80 x ILC-2394 & 94 & 68.2 & 25.1 & 62.4 \\
\hline C-80 x ILC-2402 & 91 & 46.6 & 36.8 & 58.1 \\
\hline $\operatorname{Lim} \min \div \max$ & $72-102.2$ & $46.6-68.2$ & $22.4-38.6$ & $49.1-64.5$ \\
\hline Mean & 91.9 & 52.8 & 31.3 & 58.7 \\
\hline $\mathrm{LSD}_{05}$ & 13.78 & 7.92 & 4.70 & 8.80 \\
\hline
\end{tabular}

38.6 pcs.), in maternal forms it decreased by 33.6 pcs. ( 29.1 pcs. on average), in testers it reduced by 67.4 pcs. (32.1 pcs. on average). Hybrid combinations C-27 x ILC-2394 (38.3 pcs.) and C-35 x ILC-2394 (38.6 pcs.) had the largest number of beans under stress conditions.

The heritability coefficient of the number of beans per plant in different hybrid populations of chickpea ranged from 38.6 to $65.1 \%$ and averaged $54.0 \%$, which indicates the possibility of breeding improvement of these traits by direct selection of valuable genotypes by phenotype already in early generations hybrids. Most of the phenotypic variability of the trait is due to genetic factors and indicates a high genetic diversity in the studied chickpea populations. Thus, selection on this basis will be highly effective.

The heritability of the studied trait changed slightly depending on the growing conditions: under favorable growing conditions, it averaged 56.8\%, in extreme conditions, it averaged $51.5 \%$, which confirms the genetic conditionality of this trait. Successful selection for this trait is possible regardless of growing conditions. 
TABLE 4: Heritability of the number of beans per plant in chickpea, $\%$

\begin{tabular}{|c|}
\hline \\
\hline C-27 x ILC-2394 \\
\hline C-27 x ILC-2402 \\
\hline C-35 x ILC-2394 \\
\hline C-35 x ILC-2402 \\
\hline C-82 x ILC-2394 \\
\hline C-82 x ILC-2402 \\
\hline C-80 x ILC-2394 \\
\hline C-80 x ILC-2402 \\
\hline Lim $\min \div \max$ \\
\hline Mean \\
\hline
\end{tabular}

\begin{tabular}{|c|}
\hline $\mathbf{2 0 1 6}$ \\
\hline 61.3 \\
\hline 65.1 \\
\hline 52.9 \\
\hline 52.1 \\
\hline 57.0 \\
\hline 50.7 \\
\hline 56.4 \\
\hline 58.9 \\
\hline $50.7-65.1$ \\
\hline 56.8 \\
\hline
\end{tabular}

\begin{tabular}{|c|}
\hline 2017 \\
\hline 58.9 \\
\hline 60.3 \\
\hline 47.3 \\
\hline 58.8 \\
\hline 47.6 \\
\hline 53.6 \\
\hline 57.2 \\
\hline 45.2 \\
\hline $45.2-60.3$ \\
\hline 53.6 \\
\hline
\end{tabular}

\begin{tabular}{|c|}
\hline 2018 \\
\hline 61.0 \\
\hline 52.6 \\
\hline 64.1 \\
\hline 42.9 \\
\hline 44.8 \\
\hline 43.9 \\
\hline 38.6 \\
\hline 64.6 \\
\hline $38.6-64.6$ \\
\hline 51.5 \\
\hline
\end{tabular}

\begin{tabular}{|c|}
\hline Mean \\
\hline 60.4 \\
\hline 59.3 \\
\hline 54.7 \\
\hline 51.3 \\
\hline 49.8 \\
\hline 49.4 \\
\hline 50.7 \\
\hline 56.2 \\
\hline $49.4-60.4$ \\
\hline 54.0 \\
\hline
\end{tabular}

\section{Discussion}

The coefficient of heritability of the mass of seeds per plant in different hybrid populations of chickpea in our studies had a low value (on average $\mathrm{H} 2=22.8 \%$ ), which is probably due to a significant proportion of paratypical variability of the trait. The low heritability of seed productivity is confirmed by the studies by Bushulyan O. V., Sichkar V. I. [17]. The strong dependence of this feature on environmental conditions is also noted by a number of scientists $[1,2,7]$. The low proportion of genotypic variability in the mass of seeds per plant indicates the low efficiency of selection of valuable forms in the splitting hybrid populations of chickpea. To eliminate the loss of highly productive plants, it is advisable to carry out individual selection in later hybrid generations.

Hybrid chickpea populations with the highest heritability of seed mass per plant should be considered the most promising in practical and breeding terms: C-35 $\times$ ILC2394 (average H2 = 26.1\%), C-80 x ILC-2394 (H2 = 26.9\%), C-27 x ILC-2394 (H2 = 24.0\%). These populations are characterized by increased genetic diversity, which makes it possible to hope for successful individual selection of productive plants in later hybrid generations under favorable cultivation conditions.

The coefficient of heritability of the number of beans per plant in hybrid populations of chickpea showed a high genetic conditionality of the trait ( $\mathrm{H} 2$ on average 54.0\%), which is consistent with the results of studies by a number of scientists $[2,4,7]$. The high heritability of the trait under study makes it possible to improve it by direct selection of valuable genotypes by phenotype already in early generations of hybrids. The genetic dependence of this trait is also confirmed by the insignificant variability of the heritability coefficient depending on the growing conditions (from 51.5\% - under extreme conditions, 
to $56.8 \%$ - under favorable conditions), which allows selection for this trait regardless of growing conditions.

Hybrid combinations of chickpeas are of practical interest for breeding as a promising genetic material for increasing the number of beans per plant: C-27 x ILC-2394 (on average $\mathrm{H} 2=60.4 \%), \mathrm{C}-27 \times$ ILC-2402 (H2 = $59.3 \%)$. These populations are characterized by increased genetic diversity, which gives hope for successful selection of chickpea plants with a high number of beans from the next generation (F3).

It should be noted that from the splitting hybrid populations of chickpea C-27 x ILC2394, C-27 x ILC-2402 and C-80 x ILC-2394, the largest number of lines was selected, characterized by a complex of selectively valuable traits, including those with increased number of beans. This proves the genetic dependence of this trait and indicates the presence of genetic diversity in the studied chickpea combinations. In total, during the study in the field, 87 lines were selected; after rejection, 34 lines continue to be studied. The results obtained are consistent with the calculations of the heritability coefficient and confirm the high efficiency of individual selections for traits with high heritability.

\section{Conclusion}

1. Economically valuable traits of chickpea in the Omsk region have unequal heritability: the mass of seeds per plant was characterized by low heritability (on average $\mathrm{H} 2=$ $22.8 \%$ ), the number of beans per plant was high (on average $\mathrm{H} 2=54.0 \%$ ).

2. The variability in the mass of seeds per plant is largely paratypical and is influenced by environmental conditions, and vice versa, in terms of the number of beans per plant, is determined by genetic factors and indicates a high genetic diversity in the studied chickpea populations.

3. Selection by weight of seeds from a chickpea plant is ineffective; it should be carried out in later hybrid generations, while the selection by the number of beans per plant is highly effective already in the early generations of hybrids.

4. The coefficient of the seed mass heritability per plant is modified by the growing conditions. Under unfavorable environmental conditions, there is an increase in the proportion of paratypical variability of the trait and a decrease in the coefficient of heritability. Selection based on seed productivity is recommended only in favorable growing conditions for the culture.

5. The following hybrid combinations of chickpeas should be considered the most promising in practical and breeding terms: 
- by weight of seeds per plant: C-35 x ILC-2394, C-80 x ILC-2394, C-27 x ILC-2394;

- by the number of beans per plant: C-27 x ILC-2394, C-27 x ILC-2402.

\section{Funding}

The studies were carried out without external funding.

\section{Acknowledgement}

The authors are grateful to the Federal Research Center of the All-Russian Institute of Plant Genetic Resources named after N.I. Vavilov for providing the source material for the study.

\section{Conflict of Interest}

The authors declare no conflicts of interest.

\section{References}

[1] Balashov, V. V. and Balashov, A.V. (2013). Volgograd Chickpea: Monograph. Volgograd: Niva.

[2] Germantseva, N. I. and Selezneva, T. V. (2018). Breeding of Chickpea for Seed Size. Agrarian Bulletin of South-East, vol. 2, issue 19, pp. 6-8.

[3] Smithson J. B., Thompson J. A. and Summerfield, R. J. (1985). Chickpea (Cicer arietinum L.) Collins, London, UK: Grain Legume Crops, p. 312-390.

[4] Kuzmina, S. P., et al. (2017). Prospects and Results of Studying the Chickpea Collection at Omsk State Agrarian University. Proceedings on Applied Botany, Genetics and Breeding, vol. 178, issue 1, pp. 48-57.

[5] Kazydub, N., Kuzmina S. and Chernenko E. (2017). Adaptability of Chickpea Collection Samples in the Southern Forest-Steppe of Western Siberia. Bulgarian Journal of Agricultural Science, vol. 23, issue 5, pp. 743-749.

[6] Vishnyakova, M. A., et al. (2019). Species Diversity of the VIR Collection of Genetic Resources of Legumes and its Use in Domestic Breeding (Review). Proceedings on Applied Botany, Genetics and Breeding, vol. 180, issue 2, pp. 109-123. 
[7] Sokolkova, A., Bulyntsev, S. and Chang, P. (2020). Genomic Analysis of Vavilov's Historic Chickpea Landraces Reveals Footprints of Environmental and Human Selection. International Journal of Molecular Sciences, vol. 21, p. 3952.

[8] Omelyanyuk, L. V. and Kalashnik, N. A. (2009). Variability and Genetic Control of Plant Productivity Depending on Hydrothermal Conditions in Pea Varieties and their F1 Hybrids from Diallel Crosses. Agricultural Biology, vol. 1, pp. 43-49.

[9] Pototskaya, I. V., et al. (2020). Phenotypic and Genotypic Assessment of Hexaploid Synthetic Wheat Lines (AABBDD) by Parameters Weevils in the Conditions of Western Siberia. Agricultural Biology, vol. 55, issue 1, pp. 15-26.

[10] Rozhanskaya, O. A., Agarkova, Z. V. and Korobova, L. N. (2002). Quantitative Variations in the Traits of Chickpea Somaclones (Cicer arietinum L.). Siberian Bulletin of Agroscience, vol. 3, issue 4, pp. 40-46.

[11] Upadhyaya, H. D., Sharma, S. and Gowda, C. L. L. (2011). Major Genes with Additive Effects for Seed Size in Kabuli Chickpea (Cicer arietinum L.). Journal of Genetics, vol. 90, pp. 479-482.

[12] Patil, S. A. and Salimath, P. M. (2010). Association of Phenological Traits with Productivity and its Components in Chickpea (Cicer arietinum L.). Legume ResearchAn International Journal, vol. 33, pp. 201-205.

[13] Monpara, B. A. and Dhameliya, H. R. (2013). Genetic Behaviour of Earliness Related Traits and Seed Yield in Chickpea (Cicer arietinum L.). Pakistan journal of biological sciences: PJBS, vol. 16, pp. 955-959.

[14] Ali, Q., et al. (2010). Genetic Variation and Association of Traits in Chickpeas (Cicer Arietinum L.). Electronic Journal of Plant Breeding, vol. 1, pp. 328-333.

[15] Ghatge, R. D. (1993). Inheritance of Seed Size in Chickpea (Cicer arietinum L.). Journal of Soils and Crops, vol. 3, pp. 56-59.

[16] Hossain, S., et al. (2010). Inheritance of Seed Size in Chickpea (Cicer arietinum L.) and Identification of QTL based on 100-seed Weight and Seed Size Index. Australian Journal of Crop Science, vol. 4, pp. 126-135.

[17] Bushulyan, O. V. and Sichkar, V. I. (2009). Chickpeas: Genetics, Breeding, Development, Technology of Growing. Odessa: SGI.

[18] Khanna-Chopra, R. and Sinha, S. K. (1987). Chickpea: Physiological Aspects of Growth and Yield. In: Saxena, M. C.; Singh, K. B. ed. The Chickpea Wallingford, UK: CAB International, pp. 163-189.

[19] Mathur, R. and Mathur, M. L. (1996). Estimation of Genetic Parameters and Interrelationship of Quantitative Traits in Chickpea. Madras Agricultural Journal, vol. 83, pp. 9-11. 
[20] Malik, B. A., Khan I. A. and Malik, M. R. (1988). Genetic Variability and Correlations among Metric Traits in Chickpea. Pakistan Journal of Agricultural Research, vol. 9, pp. 352-354.

[21] Mukhordova, M. E. (2015). Heritability of Economically Valuable Traits of Winter Bread Wheat Hybrids. Bulletin of Altai State Agrarian University, vol. 7, issue 129, pp. 20-24.

[22] Yusov, V. S. and Evdokimov, M. G. (2015). Heritability of Morphological Traits of Lodging Resistance in Durum Wheat in the Forest-Steppe Conditions of Western Siberia. Bulletin of Altai State Agrarian University, vol. 7, issue 129, pp. 24-30.

[23] Mahmud, I. and Kramer, H. H. (1951). Segregation for Yield, Height and Maturity Following A Soybean Cross. Agronomy Journal, vol. 43, issue 12, pp. 605-609. 